\title{
Toward a better understanding of the comparatively high prostate cancer incidence rates in Utah
}

\author{
Ray M Merrill*1,2, Sterling C Hilton ${ }^{3}$, Charles L Wiggins ${ }^{4}$ and \\ Jared D Sturgeon ${ }^{3}$
}

\begin{abstract}
Address: ${ }^{1}$ Department of Health Science, College of Health and Human Performance, Brigham Young University, Provo, Utah, USA, ${ }^{2}$ Department of Family and Preventive Medicine, University of Utah College of Medicine, USA, ${ }^{3}$ Department of Statistics, College of Physical and Mathematical Sciences, Brigham Young University, Provo, Utah, USA and ${ }^{4}$ Utah Cancer Registry, Department of Oncological Sciences, and Huntsman Cancer Institute, University of Utah, Salt Lake City, Utah, USA

Email: Ray M Merrill* - Ray_Merrill@byu.edu; Sterling C Hilton - hiltons@byu.edu; Charles L Wiggins - Chuck.Wiggins@hsc.utah.edu; Jared D Sturgeon - sturg008@umn.edu

* Corresponding author
\end{abstract}

Published: 29 April 2003

BMC Cancer 2003, 3:14
Received: 2I August 2002

Accepted: 29 April 2003

This article is available from: http://www.biomedcentral.com/I47/-2407/3//4

(C) 2003 Merrill et al; licensee BioMed Central Ltd. This is an Open Access article: verbatim copying and redistribution of this article are permitted in all media for any purpose, provided this notice is preserved along with the article's original URL.

\begin{abstract}
Background: This study assesses whether comparatively high prostate cancer incidence rates among white men in Utah represent higher rates among members of the Church of Jesus Christ of Latter-day Saints (LDS or Mormons), who comprise about 70\% of the state's male population, and considers the potential influence screening has on these rates.
\end{abstract}

Methods: Analyses are based on 14,693 histologically confirmed invasive prostate cancer cases among men aged 50 years and older identified through the Utah Cancer Registry between 1985 and 1999. Cancer records were linked to LDS Church membership records to determine LDS status. Poisson regression was used to derive rate ratios of LDS to nonLDS prostate cancer incidence, adjusted for age, disease stage, calendar time, and incidental detection.

Results: LDS men had a 31\% (95\% confidence interval, 26\% - 36\%) higher incidence rate of prostate cancer than nonLDS men during the study period. Rates were consistently higher among LDS men over time (1 18\% in 1985-88, 20\% in 1989-92, $15 \%$ in 1993-1996, and $13 \%$ in 1997-99); age ( $13 \%$ in ages $50-59,48 \%$ in ages $60-69,28 \%$ in ages $70-79$, and $16 \%$ in ages 80 and older); and stage (36\% in local/regional and $17 \%$ in unstaged). An age- and stage-shift was observed for both LDS and nonLDS men, although more pronounced among LDS men.

Conclusions: Comparatively high prostate cancer incidence rates among LDS men in Utah are explained, at least in part, by more aggressive screening among these men.

\section{Background}

Among the 11 cancer registries that contract with the Surveillance, Epidemiology, and End Results (SEER) Program of the US National Cancer Institute, the Utah Cancer Reg- istry reports the lowest overall incidence of cancer. During the years 1995-1999, age-adjusted (to the 2000 US population) invasive cancer incidence rates in white men for the leading 10 sites, per 100,000 person-years, were 393.1 
in Utah compared with 451.0 in SEER (without Utah) [1]. Lower rates in Utah were observed for all sites except prostate cancer and melanoma of the skin (174.5 vs. 157.8 for prostate, 42.7 vs. 81.9 for lung and bronchus, 48.8 vs. 63.9 for colon and rectum, 31.7 vs. 38.8 for urinary bladder, 22.4 vs. 24.6 for non-Hodgkin's lymphoma, 25.3 vs. 23.4 for melanoma of the skin, 13.0 vs. 16.3 for oral cavity and pharynx, 11.0 vs. 15.5 for kidney and renal pelvis, 13.9 vs. 16.7 for leukemia, and 9.9 vs. 12.2 for pancreas). Comparatively high prostate cancer incidence rates in the 1990 s among white men in Utah have been reported previously $[2,3]$.

In 1847, members of the Church of Jesus Christ of Latterday Saints (LDS or Mormon) settled the Salt Lake Valley in northern Utah [4]. Over the next several years, LDS Church members settled over 350 communities throughout the territory. Today, about $70 \%$ of Utah's 2.2 million population is affiliated with the LDS Church $[5,6]$. Over $85 \%$ of the state's population is white, non-Hispanic [6]. Low cigarette-smoking and alcohol-drinking prevalence observed among LDS helps explain the comparatively low rates for many of these cancer sites in Utah [5]. Whether the high prostate cancer incidence rates reflect higher rates among LDS is unclear.

We linked electronic records from the LDS Church membership files and the Utah Cancer Registry to examine the magnitude and temporal trends in prostate cancer incidence rates among LDS and nonLDS residents of Utah for the calendar years 1985 through 1999. Cases judged to have been incidentally detected through transurethral resection of the prostate (TURP), a procedure typically used to treat obstructive uropathy, were also identified and considered in the rate calculations to provide a clearer indication of the effect of screening on the incidence rates of prostate cancer. We also examined results from a statewide health survey to characterize prostate-specific antigen screening patterns by religious affiliation.

\section{Methods}

We combined information from LDS Church membership records and the population-based Utah Cancer Registry to calculate prostate cancer incidence rates for LDS and nonLDS populations in Utah during the period 1985-99. We also examined results from a statewide health survey to characterize PSA screening patterns in these two groups.

\section{Utah Cancer Registry}

The population-based Utah Cancer Registry (UCR) was established in 1966 and has continuously participated in the National Cancer Institute's Surveillance, Epidemiology, and End Results (SEER) program since 1973. UCR staff members and local cancer registrars identify incident cases of cancer among Utah residents through routine and systematic review of pathology reports, medical records, radiation therapy records, hospital discharge lists, and vital records. Tumor characteristics including histology, grade, and primary site are coded according to the International Classification of Disease for Oncology-Second Edition (ICDO-2) [7]. Categories of stage of disease at diagnosis are documented in the Summary Staging Guide of the SEER program of the National Cancer Institute [8]. Registry records also include information regarding treatment and patient characteristics such as age at diagnosis, gender, race/ethnicity, and place of residence at diagnosis. Information regarding patient characteristics, cancer diagnosis, and treatment is ascertained from specific statements in medical records, reports from private pathology laboratories and radiotherapy units, and death certificates. Cancer surveillance in Utah is conducted in accordance with standards instituted by the SEER program and the North American Association of Central Cancer Registries $[9,10]$.

\section{Linkage of cancer data with LDS church records}

UCR records were linked to LDS Church membership records to determine membership in the LDS Church. The linkage process took place under direct supervision of the Church and the UCR and was conducted in the Church's Member and Statistical Records Department. Confidentiality of record information was strictly enforced. After the records were linked, all personal identifying information was stripped from the database.

Records were linked using the probabilistic linking program LinkPro [11]. The program calculates probabilities to identify whether a pair of records refers to the same person. Ten variables that were common to both sets of records were used to link the records: first, middle, and last names; birth day; birth month; birth year; gender; zip code; vital status; and maiden name. SOUNDEX versions of the names were used in the matching process, while actual names were used in the review process.

There were 121,967 incident cases of cancer identified in the UCR database from 1973 to 2000 and approximately 6.6 million records in the LDS Church database. Records were linked in three stages. The first stage linked all records that matched exactly on first, middle, and last names; complete birth date; and gender. There were 36,187 such records declared matches without review. The second stage consisted of taking the remaining records and forcing them to link on last name and at least five additional variables. The 6,652 records that linked on eight additional variables were declared matches without review. Of the 18,587 records that linked on seven additional variables, 17,612 were declared matches without review, and 975 were reviewed with 859 declared 
matches. Of the 21,146 records that linked on six additional variables, 14,378 were declared matches without review, and 6,768 were reviewed of which 2,812 were declared matches. Finally, of the 22,492 records that matched on five additional variables, 1,650 were declared matches without review, 5,629 were reviewed with 1,328 declared matches, and 15,213 were declared non-matches without review. The third stage of the linkage process consisted of taking the remaining unlinked records and forcing them to link on first name and at least six other additional variables. There were 3,338 such records. All were reviewed, with 380 declared matches. These stages resulted in 81,617 (68\%) of the UCR records being linked to a Church record.

\section{Data}

All incident cases of prostate cancer (ICDO-2 site code C61.9) that were diagnosed among Utah residents during the time period 1985-99 were identified from records of the Utah Cancer Registry. Lymphomas of the prostate (ICDO-2 histologies 9590-9989) were excluded from the study. Analyses were further restricted to histologically confirmed cases that were 50 years and older at the time of prostate cancer diagnosis. Stage categories of disease at diagnosis were local/regional, distant, and unstaged. Local and regional stages were combined because of the large proportion of cases upsataged because of surgery [12].

\section{TURP and Incidental Detection}

Although the UCR has historically collected surgery information on cancer cases, including whether a prostate cancer case underwent a TURP, not until 1998 did they identify whether the TURP led to or was the result of a prostate cancer diagnosis. This change in the level of information collected was made among all the registries participating in the SEER program. In the UCR during 1998-99, the proportion of TURPs performed among cases resulting in an incidental finding because of the surgery for benign disease was 0.6786 . The log of the odds in favor of this event was then regressed on age using logistic regression. Age was not statistically significant (i.e., Chi-square = $1.0237, \mathrm{p}=0.3116)$. Age and age-squared terms were also fit in the model, but neither was statistically significant. Because the proportion of incidental detection among cases undergoing a TURP was not associated with age, we multiplied in each age category for each year 1985 through 1997 the proportion 0.6786 by the total number of age- and year-specific TURPs recorded among cases to get an estimate of the number of TURPs that led to a prostate cancer diagnosis.

\section{Utah Health Status Survey}

The 1996 Utah Health Status Survey is a cross-sectional random survey sponsored by the Utah Department of
Health. The Gallup Organization collected the data by incorporating a telephone survey instrument into a computer-assisted, random-digit-dialing software program called SURVENT. Supervised interviews were conducted across twelve local health districts in Utah by trained interviewers. Although the survey questionnaire covered several topics, we only used data from questions on PSA screening and religious status. The interview process occurred during June 1 through August 31, 1996. Interviews were conducted with one randomly selected adult aged 18 years or older in each household. If required, as many as nine telephone attempts were made to contact a selected household. The response rate was $66.3 \%$. In order to more accurately generalize the survey results to the Utah population, post-survey weighting adjustments were made. Adjustments weighted the sample to be proportionally consistent with age, sex, geographic, and Hispanic status distributions of the 1996 Utah population.

\section{Statistical analysis}

Age-adjusted prostate cancer incidence rates were calculated for individual calendar years and for the following year groups: 1985-88, 1989-92, 1993-96, and 1997-99. These rates were calculated by the direct method with the United States standard population for the year 2000 [13]. Rates were calculated for both LDS and nonLDS populations in Utah and are expressed per 100,000 person-years. The Member and Statistical Records Department of the LDS Church provided annual age- and sex-specific estimates of the number of LDS Church members in Utah (Larry Elkington, Manager of Church Management Information Center, personal communication). Estimates for the nonLDS population of Utah were derived by subtracting the number of LDS Church members from the Utah population provided by the US Bureau of the Census [14]. Poisson regression was used to estimate the incidence rate ratio between LDS and nonLDS [15]. Appropriate models reported below were selected based on the deviance goodness-of-fit test. Analyses were performed with standard packages of the Statistical Analysis System (SAS) [16].

\section{Results}

A total of 14,693 incident cases of histologically confirmed invasive prostate cancer in men aged 50 years and older were diagnosed among Utah residents during the period 1985-99. Based on linkage with LDS Church records, $11,291(76.8 \%)$ of these cases were determined to be LDS Church members. There were 12,088 (82.3\%) with local/regional stage, 1,009 (6.9\%) with distant stage, and $1,594(10.8 \%)$ with unstaged prostate cancer. Two cases had missing stage information.

The frequency of cases is presented according to religious preference, calendar year, and age in Table 1. For both LDS and nonLDS, a shift occurred over time from cases 
Table I: Frequency of invasive prostate cancer cases diagnosed in Utah among men aged 50 years and older according to religious preference (LDS vs. nonLDS), calendar year, and age

\begin{tabular}{|c|c|c|c|c|c|c|c|c|c|c|c|c|c|c|c|c|}
\hline \multirow[b]{3}{*}{ Age } & \multicolumn{4}{|c|}{$1985-88$} & \multicolumn{4}{|c|}{ 1989-92 } & \multicolumn{4}{|c|}{$1993-96$} & \multicolumn{4}{|c|}{$1997-99$} \\
\hline & \multicolumn{2}{|c|}{ LDS } & \multicolumn{2}{|c|}{ NonLDS } & \multicolumn{2}{|c|}{ LDS } & \multicolumn{2}{|c|}{ NonLDS } & \multicolumn{2}{|c|}{ LDS } & \multicolumn{2}{|c|}{ NonLDS } & \multicolumn{2}{|c|}{ LDS } & \multicolumn{2}{|c|}{ NonLDS } \\
\hline & No. & $\%$ & No. & $\%$ & No. & $\%$ & No. & $\%$ & No. & $\%$ & No. & $\%$ & No. & $\%$ & No. & $\%$ \\
\hline $50-59$ & 124 & 6.0 & 45 & 8.0 & 250 & 7.4 & 81 & 8.5 & 332 & 10.4 & 144 & 14.0 & 357 & 13.5 & 123 & 14.3 \\
\hline $60-69$ & 636 & 30.9 & 197 & 34.9 & 1113 & 33.0 & 270 & 28.5 & 1198 & 37.3 & 373 & 36.2 & 974 & 36.7 & 309 & 36.0 \\
\hline $70-79$ & 918 & 44.7 & 229 & 40.6 & 1442 & 42.7 & 449 & 47.4 & 1235 & 38.5 & 395 & 38.3 & 996 & 37.6 & 324 & 37.7 \\
\hline $80+$ & 378 & 18.4 & 93 & 16.5 & 570 & 16.9 & 148 & 15.6 & 444 & 13.8 & 119 & 11.5 & 324 & 12.2 & 103 & 12.0 \\
\hline $\begin{array}{l}\text { Chi-square MH } \\
\text { Trend Chi- } \\
\text { square }\end{array}$ & \multicolumn{4}{|c|}{$\begin{aligned} 7.36, p= & 0.06116 .13, p= \\
& 0.0128\end{aligned}$} & \multicolumn{4}{|c|}{$\begin{aligned} 10.29, p= & 0.01620 .09, p= \\
& 0.7581\end{aligned}$} & \multicolumn{4}{|c|}{$\begin{aligned} 12.49, p= & 0.00597 .42, p= \\
& 0.0064\end{aligned}$} & \multicolumn{4}{|c|}{$\begin{aligned} 0.48, p= & 0.92290 .12, p= \\
& 0.7342\end{aligned}$} \\
\hline
\end{tabular}

Table 2: Frequency of prostate cancer cases diagnosed in Utah among men aged 50 years and older according to religious preference (LDS vs. non LDS), calendar year, and summary stage

\begin{tabular}{|c|c|c|c|c|c|c|c|c|c|c|c|c|c|c|c|c|}
\hline \multirow[b]{3}{*}{ Age } & \multicolumn{4}{|c|}{$1985-88$} & \multicolumn{4}{|c|}{ 1989-92 } & \multicolumn{4}{|c|}{$1993-96$} & \multicolumn{4}{|c|}{ 1997-99 } \\
\hline & \multicolumn{2}{|c|}{ LDS } & \multicolumn{2}{|c|}{ NonLDS } & \multicolumn{2}{|c|}{ LDS } & \multicolumn{2}{|c|}{ NonLDS } & \multicolumn{2}{|c|}{ LDS } & \multicolumn{2}{|c|}{ NonLDS } & \multicolumn{2}{|c|}{ LDS } & \multicolumn{2}{|c|}{ NonLDS } \\
\hline & No. & $\%$ & No. & $\%$ & No. & $\%$ & No. & $\%$ & No. & $\%$ & No. & $\%$ & No. & $\%$ & No. & $\%$ \\
\hline Local/Regional & 1475 & 71.7 & 389 & 69.0 & 2608 & 77.3 & 687 & 72.5 & 2671 & 83.2 & 863 & 83.7 & 2573 & 97.1 & 822 & 95.8 \\
\hline Distant & 238 & 11.6 & 85 & 15.1 & 275 & 8.1 & 100 & 10.5 & 162 & 5.1 & 57 & 5.5 & 64 & 2.4 & 28 & 3.3 \\
\hline Unstaged & 343 & 16.7 & 90 & 15.9 & 492 & 14.6 & 161 & 17.0 & 376 & 11.7 & 111 & 10.8 & 13 & 0.5 & 8 & 0.9 \\
\hline Chi-square & & $.00, p=$ & .0819 & & & $.99, p$ & .0068 & & & 98, p & 0.6116 & & & $00, \mathrm{p}$ & 0.1351 & \\
\hline
\end{tabular}

being diagnosed at older ages to younger ages. For the first three time periods, LDS compared with nonLDS cases were less likely to be diagnosed in their $50 \mathrm{~s}$ and more likely to be diagnosed in their $80 \mathrm{~s}$. The frequency of cases is also presented according to religious preference, calendar year, and stage (Table 2). A noticeable stage shift occurred from distant to local/regional disease over time for both LDS and nonLDS cases. Only in the years 1989 through 1992 do LDS cases have a significantly higher percentage diagnosed with local/regional disease.

Local/regional-staged TURP- and nonTURP-detected ageadjusted prostate cancer incidence rates for men 50 years of age and older in Utah are presented according to religious preference and calendar year (Figure 1). NonTURPdetected prostate cancer incidence rates are generally higher for LDS men across the years, particularly during the PSA-induced peak. Despite this observation, TURP-detected prostate cancer incidence rates are similar. Distantstaged age-adjusted prostate cancer incidence rates for men 50 years of age and older in Utah are also presented by religious preference and calendar year (Figure 2). These rates are generally similar.

A Poisson regression model, adjusted for age and stage at diagnosis, calendar time, and whether prostate cancer was TURP- or nonTURP-detected, indicated that LDS compared with nonLDS have 1.31 (95\% confidence interval, 1.26 - 1.36) times the incidence rate of prostate cancer among men aged 50 years and older in Utah. The adjusted Poisson regression model gave rate ratios of LDS to nonLDS of $2.18(1.99-2.40)$ in $1985-88,1.20(1.12-$ $1.29)$ in $1989-92,1.15(1.08-1.24)$ in 1993-1996, and $1.13(1.04-1.22)$ in $1997-99$. Adjusted rate ratios also indicated significantly higher rates for LDS compared with nonLDS for each age group [1.13 (1.01-1.27) in ages 50$59,1.48(1.38-1.58)$ in ages $60-69,1.28(1.21-1.36)$ in ages $70-79$, and $1.16(1.04-1.28)$ in ages 80 and older] and for certain stage categories [1.36 (1.31-1.43) in local/ regional stage, $0.97(0.84-1.11)$ in distant stage, and 1.17 (1.04-1.31) in unstaged]. 


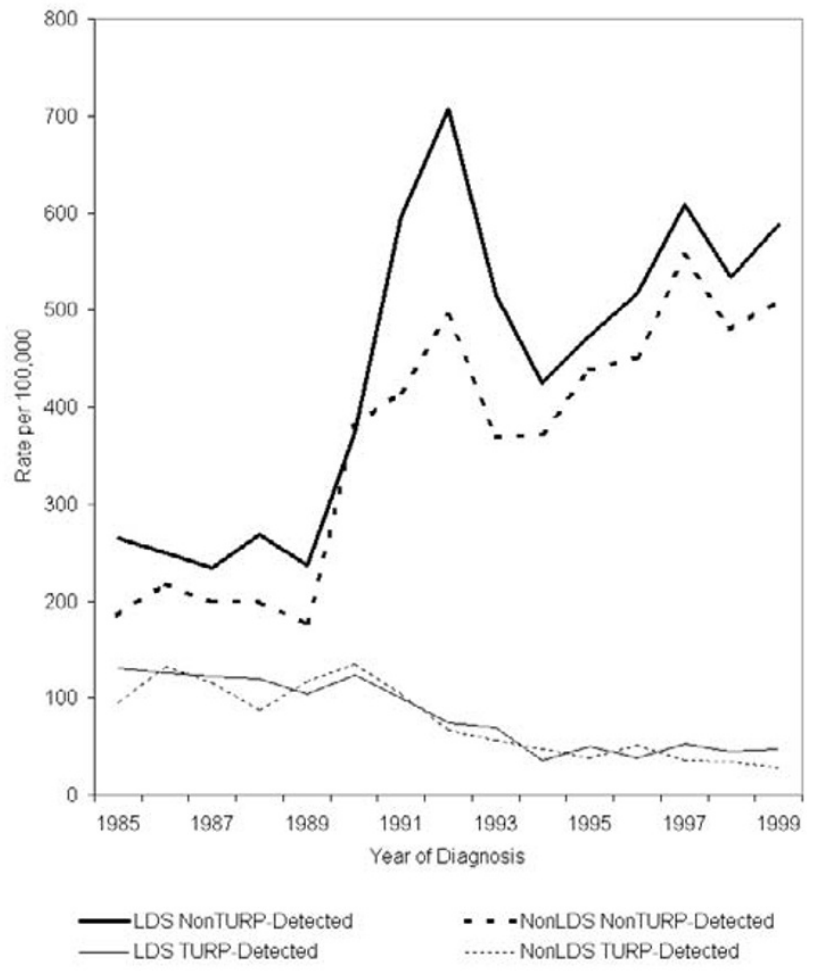

Figure I

Age-adjusted (to the 2000 US standard population) TURPand nonTURP-detected local/regional staged prostate cancer incidence rates for men aged 50 years and older in Utah according to religious preference and year of diagnosis
Finally, on the basis of the 1996 Utah Health Status Survey, LDS men compared with nonLDS men were more likely to have received a PSA screen in the previous year (Table 3).

\section{Discussion}

Evidence that prostate cancer incidence rates are sensitive to screening is well established [2,3,17-20]. Potosky et al. examined the potential influence that adoption of transrectal ultrasound (TRUS) and PSA testing had on increasing prostate needle biopsy rates in the SEER areas from 1986 through 1991 [17]. Both TRUS and PSA testing rates, initially near zero, increased to almost 2,000 and 20,000 per 100,000, respectively. Their study further showed a correlation between increasing needle biopsy rates and prostate cancer incidence rates. Legler $e t$ al. added to our understanding of the role of PSA testing on prostate cancer incidence rates by showing that first time PSA testing proportions, not the overall PSA proportion, track closely

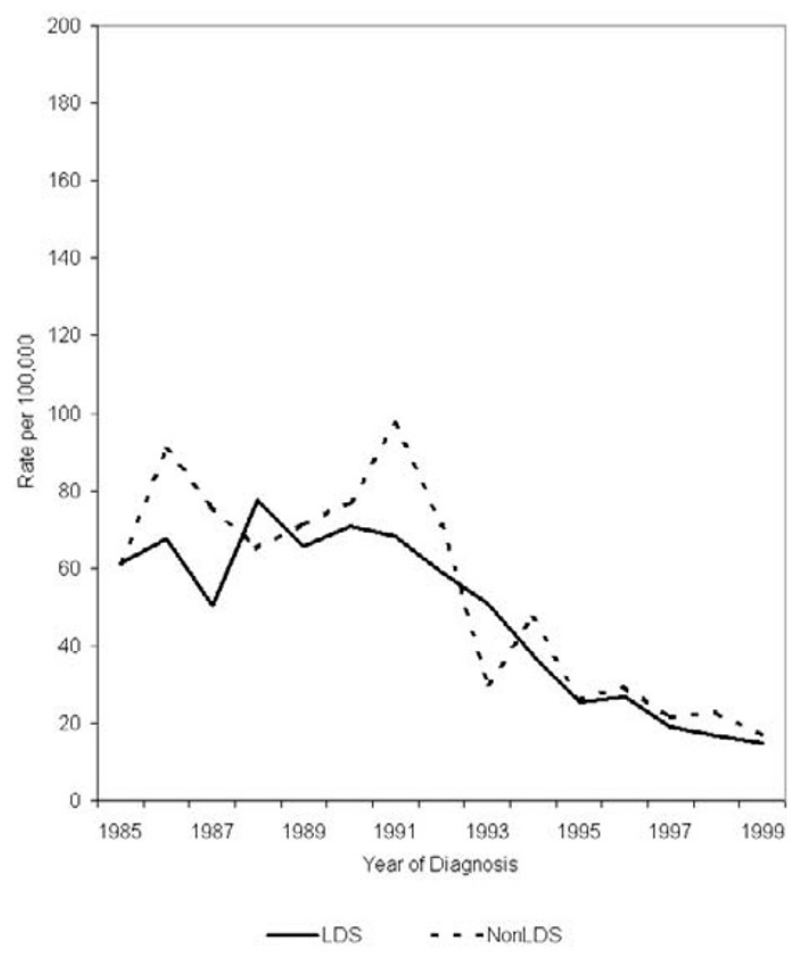

Figure 2

Age-adjusted (to the 2000 US standard population) distant staged prostate cancer incidence rates for men aged 50 years and older in Utah according to religious preference and year of diagnosis

with prostate cancer incidence rates [20]. In a comparison of prostate cancer incidence rates among white men in five of the SEER areas (Detroit, Utah, Seattle-Puget Sound, Iowa, and Connecticut), Brawley showed that the rates were highest in Seattle from 1986 through 1991, but then highest in Utah from 1992 through 1994 [21]. In a consistent manner, the proportion of men receiving a first time PSA tended to be highest in Seattle in the earlier years but highest in Utah in the later years [20]. Because 76.8\% of diagnosed prostate cancer cases in Utah during our study period were in LDS men, we may assume that the relatively high proportion of first time PSA tests in Utah primarily reflects LDS men.

The results, based on Poisson regression, indicate that LDS men compared with nonLDS men residing in Utah, after adjusting for age and stage at diagnosis, calendar time and TURP experienced significantly higher prostate cancer incidence rates. Unfortunately, our broad stage cat- 
Table 3: Percentage of men aged 50 years and older receiving a PSA test in the past year according to LDS status and age

\begin{tabular}{|c|c|c|c|c|}
\hline \multirow{2}{*}{$\begin{array}{l}\text { LDS } \\
\text { Status }\end{array}$} & \multicolumn{4}{|c|}{ Age Group } \\
\hline & $50-59$ & $60-69$ & $70+*$ & $50+$ \\
\hline LDS & $134 / 240(55.8 \%)$ & $151 / 212$ (71.2\%) & $116 / 162$ (71.6\%) & $401 / 614(65.3 \%)$ \\
\hline NonLDS & $54 / 102(52.9 \%)$ & $37 / 59(62.7 \%)$ & $28 / 43(65.1 \%)$ & I I 9/204 (58.3\%) \\
\hline
\end{tabular}

*Because of small numbers among nonLDS in the age group 80+, age groups 70-79 and 80+ were combined. Bold-typed represent significantly greater PSA testing among LDS compared with nonLDS, based on a one-sided hypothesis test and the 0.05 level of significance.

egories limited our ability to adjust for this variable such that differences in stage could still be explaining some of the higher incidence among LDS men. Nevertheless, the higher rates among LDS men could be because they more readily adopted TRUS and digital rectal exams in the first time period, prior to widespread PSA screening, and then more readily adopted PSA screening but to a lesser degree. Historically, physicians have used digital rectal examinations in early detection efforts $[22,23]$. In general, digital rectal examination has a $1-2 \%$ detection rate and the PSA test, which is relatively easy to perform, has a 3\% detection rate in men who are older than 50 years of age [24].

Screening is further implicated by the fact that the higher rate ratios of LDS to nonLDS prostate cancer incidence occur in local/regional stage cases. Age- and stage-shifts in the data are also consistent with higher levels of screening among LDS men. Unfortunately, there is little screening data available to allow us to directly evaluate the role screening plays in the higher prostate cancer incidence rates observed among LDS men. Nevertheless, based on the 1996 Utah Health Status Survey we showed that LDS men compared with nonLDS men were more likely to have received a PSA test in the past year, overall and within age categories. Yet the order of PSA received, whether a first or subsequent PSA test, is unknown. In addition, we do not know whether higher PSA screening use among LDS men remained higher prior to or after 1996.

Studies have shown that men undergoing PSA screening are more likely to display an overall constellation of health-promoting behavior, such as not smoking and seeking health care regularly $[25,26]$. Smokers are less likely to use medical services $[27,28]$, with one study finding that $76 \%$ of nonsmokers compared with $64 \%$ of smokers receiving regular checkups [26]. Utah has historically experienced the lowest smoking prevalence in the United States [29]. Utah smoking prevalence is currently closest to the Healthy People 2010 goal for the nation of $12 \%$ [30], with smoking prevalence in the year 2000 of $12.9 \%$ compared with the next lowest prevalence in California of 17.2 and nationally of $23.2 \%$ [31]. This low smoking prevalence is primarily explained by the over
$70 \%$ LDS population who attend church weekly, among which less than $1 \%$ are current smokers [5]. Men who are married and who have medical insurance have the highest levels of PSA use in Utah [25]. According to the 1996 Utah Health Status Survey, $74.7 \%$ of LDS men and $58.9 \%$ of nonLDS men in Utah were married, and $92.2 \%$ of LDS men compared with $86.2 \%$ of nonLDS men were medically insured [32].

In a consistent manner, studies have found that men who are generally healthier [26,33], married [34,35], and more educated $[35,36]$ are more likely to be diagnosed with prostate cancer than men with different characteristics. Yet these men also tend to experience better survival [35,37$39]$, indicating that they are possibly being diagnosed at earlier stages because of more aggressive screening. In addition to LDS having comparatively low smoking prevalence, a higher proportion who are married, and a higher proportion who are medically insured, 95\% of LDS men compared with $89 \%$ of nonLDS men reported having at least a high school education, according to the 1996 Health Status Survey [32].

In our study, adjusting for TURP-detected cases allowed us to better assess the influence of screening on prostate cancer incidence trends. Frequent use of TURP for benign prostatic hyperplasia in the 1970s and 1980s and the rapid introduction and widespread adoption of PSA screening beginning in the late 1980s, tapped an extensive pool of latent and preclinical prostate disease $[40,41]$. Consistent with another study, we found that in the mid 1980s up to $50 \%$ or more of all prostate cancer cases were incidentally detected through TURPs [41]. However, as medications with few side effects became available to treat benign prostatic hypterplasia and PSA screening became widely adopted, TURP-detected cases declined from their peak in 1987 through 1993 [41]. Our results showed a similar decline in the TURP-detected prostate cancer incidence rates, followed by a leveling off between 1994 and 1999, for both LDS and nonLDS cases in Utah. We also found the level of TURP-detected rates to be very similar between LDS and nonLDS. 
Data are not available to identify whether TURP rates differed between LDS and nonLDS. However, if we assume they were similar or even higher among LDS, and given the similar TURP-detected prostate cancer incidence rates observed, there is no reason to believe that prostate cancer is more common in LDS men. Indeed, an older study based on Utah data covering the years 1971 through 1985 found that the age-adjusted (to the 1970 US standard) prostate cancer incidence rates per 100,000 person-years were 76.3 for LDS compared with 109.1 for nonLDS [42].

One goal of screening is to identify the presence of disease before it becomes clinically evident. If PSA-based screening achieved this goal, we would anticipate dramatic increases in the number of cases diagnosed with early stage prostate cancer. The available data did not allow us to restrict our analyses to cases with just localized disease. Results from previous studies have demonstrated that choice of therapy for prostate cancer may influence subsequent determination of staging. Specifically, many patients that clinically appeared to have localized disease were determined to have regional stage disease based on pathological review of tissue that was obtained from radical prostatectomy $[43,44]$. Similar patients that did not undergo aggressive surgical treatment would not have had the opportunity for a comparable evaluation of stage; the latter group of patients would have remained classified with localized disease. Therefore, it was not possible in these data to distinguish between cases with true localized disease and those who received a clinical diagnosis of localized disease but actually had undetected regional stage disease. Hence, cases of local and regional stage disease were combined in the present study.

\section{Conclusion}

LDS men compared with nonLDS men may have adopted digital rectal and PSA screening more readily. Higher PSA screening was observed among LDS, both overall and within selected age groups according to the 1996 Utah Health Status Survey. In addition, individuals in the LDS Church tend to reflect a host of characteristics (i.e., low smoking prevalence, a high proportion married, a high proportion medically insured, and a high level of education) that are associated with good general health. Previous studies have indicated that these characteristics are associated with more aggressive PSA screening and, because of the high prevalence of asymptomatic prostate cancer in the population, subsequent prostate cancer diagnosis. If LDS men adopted screening more readily, we may expect that they would have experienced higher prostate cancer incidence rates. Evidence in this paper indicates that the comparatively high prostate cancer incidence rates in Utah are likely due to, at least in part, more aggressive screening among LDS.

\section{Acknowledgements}

This study was supported in part by the National Cancer Institute (Contract No. NOI-PC-67000). It was also supported by the Charles Redd Center for Western Studies. We wish to thank Bob Anderson and Larry Elkington from the LDS Church for their assistance in linking the Utah cancer data with LDS Church records. We also wish to thank Lois Haggard for making available to us the 1996 Utah Health Status Survey data.

\section{References}

I. SEER*Stat 4.2. SEER Cancer Incidence Public-Use Database, 1973-1999. November 200I Submission Bethesda, MD (USA): US Department of Health and Human Services. National Institutes of Health

2. Merrill RM, Potosky AL and Feuer EJ Changing trends in U.S. prostate cancer incidence rates I Natl Cancer Inst 1996, 88(22): 1683-5

3. Merrill RM and Brawley OW Prostate cancer incidence and mortality rates among white and black men Epidemiology 1997 , 8(2):|26-3|

4. McCormick JS In Utah History Encyclopedia (Edited by: Powell AK) Salt Lake City 1999, [http://www.media.utah.edu/UHE/s/SALTLAKEC ITY.html]

5. Merrill RM and Thygerson AL Physical activity in Utah according to religion and church attendance Preventive Medicine 200I, 33(I):38-45

6. US Census Bureau 2001 population estimates [http://quick facts.census.gov/gfd/states/49000.html]

7. Percy C, Van Holten V, Muir C and editors International Classification of Diseases for Oncology, Second Edition World Health Organization. Geneva 1990,

8. Shambaugh EM, Weiss MA and Axtell LM Summary Staging Guide for the Cancer Surveillance, Epidemiology, and End Results (SEER) Program US Department of Health and Human Services. Public Health Service. National Institutes of Health. NIH Publication No. 8I-23 I3. January 198I,

9. Ries L, Fritz A and editors The SEER Program Code Manual. Third Edition Surveillance Program, Division of Cancer Control and Population Sciences, National Cancer Institute, National Institutes of Health. Bethesda, MD 1998,

10. North American Association of Central Cancer Registries. Standards for Cancer Registries. Volume III Standards for Completeness, Quality, Analysis, and Management of Data September 2000

II. Wajda A, Roos LL and Layefsky M Record linkage strategies: Part II. Portable software and deterministic matching Methods Inf Med 199I, 30(3):210-4

12. Merrill RM Upstaging of prostate cancer due to radical prostatectomy: a population-based analysis UroOncology 200I, I:243-50

13. Kahn HA and Sempos CT Statistical Methods in Epidemiology Monographs in Epidemiology and Biostatistics New York: Oxford University Press 1989, 12:

14. US Bureau of the Census U.S. Populations [http://seer.cancer.gov/ popdata/download.html]

15. McCullagh P and Nelder JA Generalized Linear Models, Second Edition London: Chapman and Hall 1989.

16. The SAS System for Windows, Proprietary Software Release 8.2 Copyright $($ 1999-200I by SAS Institute Inc., Cary, NC, USA

17. Potosky AL, Miller BA, Albertsen PC and Kramer BS The role of increasing detection in the rising incidence of prostate cancer JAMA 1995, 273(7):548-52

18. Labrie F, Dupont A, Suburu R, Cusan L, Tremblay M, Gomez JL and Emond $J$ Serum prostate specific antigen as pre-screening test for prostate cancer J Urol 1992, I47(3 Pt 2):846-52

19. Catalona WJ, Smith DS, Ratliff TL and Basler JW Detection of organ-confined prostate cancer is increased through prostatespecific antigen-based screening JAMA 1993, 270(8):948-54

20. Legler JM, Feuer EJ, Potosky AL, Merrill RM and Kramer BS The role of prostate-specific antigen (PSA) testing patterns in the recent prostate cancer incidence decline in the United States Cancer Causes Control 1998, 9(5):519-27

21. Brawley OW Prostate carcinoma incidence and patient mortality: the effect of screening and early detection Cancer 1997, 80(9): $1857-63$ 
22. Gerber GS, Thompson IM, Thisted R and Chodak GW Disease-specific survival following routine prostate cancer screening by digital rectal examination JAMA I993, 269:6I-4

23. Friedman GD, Hiatt RA, Quesenberry CP and Selby JV Case-control study of screening for prostatic cancer by digital rectal examinations Lancet 1991, 337:1526-9

24. Clinical Guideline: Part III Screening for prostate cancer. Ann Intern Med 1997, I 26:480-4[http://www.acponline.org/journals/annals/ I5mar97/ppscreen.htm]

25. Merrill RM Demographics and health-related factors of men receiving prostate-specific antigen screening in Utah Prev Med 200I, 33(6):646-52

26. Lemon S, Zapka J, Puleo E, Luckmann R and Chasan-Taber L Colorectal cancer screening participation: comparisons with mammography and prostate-specific antigen screening $\mathrm{Am} J$ Public Health 2001, 91:1264-72

27. Hofer T and Katz S Healthy behaviors among women in the United States and Ontario: the effect on use of preventive care Am J Public Health 1996, 86( I 2): I755-9

28. Kiefe C, Williams O, Greenlund K, Ulene V, Gardin J and Raczynski J Health care access and seven-year change in cigarette smoking. The CARDIA Study Am J Prev Med 1998, I 5(2): | 46-54

29. Merrill RM, Lindsay GB and Lyon JL Tobacco-related cancers in Utah compared to the United States: quantifying the benefits of the Word of Wisdom BYU Studies 1999, 38:91-105

30. US Department of Health and Human Services. Healthy People 2000 National Health Promotion and Disease Prevention Objectives Rockville, Md: US Department of Health and Human Services, Public Health Service 1990,

31. Tobacco use - $\mathbf{2 0 0 0}$ Behavior Risk Factor Surveillance System, Prevalence Data, Nationwide 2000, [http://apps.nccd.cdc.gov/brfss/ list.asp? cat $=$ TU\&yr $=2000 \&$ qkey $=621$ \&state $=$ US]

32. 1996 Utah Health Status Survey Public Use Data Bureau of Surveillance and Analysis, Office of Public Health Data, Utah Department of Health

33. Mills PK, Beeson WL, Phillips RL and Fraser GE Cancer incidence among California Seventh-Day Adventists, I976-1982 Am J Clin Nutr 1994, 59(5 Suppl): I I36S- I I42S

34. La Vecchia C, Franceschi S, Talamini R, Negri E, Boyle P and D'Avanzo $B$ Marital status, indicators of sexual activity and prostatic cancer J Epidemiol Community Health 1993, 47(6):450-3

35. Harvei $S$ and Kravdal $O$ The importance of marital and socioeconomic status in incidence and survival of prostate cancer. An analysis of complete Norwegian birth cohorts Prev Med 1997, 26(5 pt I):623-32

36. Mandel JS and Schuman LM Sexual factors and prostatic cancer: results from a case-control study / Gerontol 1987, 42(3):259-64

37. Krongrad A, Lai H, Burke MA, Goodkin K and Lai S Marriage and morality in prostate cancer J Urol 1996, I56(5): I696-70

38. Krongrad A, Lai $H$ and Lai S Variation in prostate cancer survival explained by significant prognostic factors I Urol 1997, I 58(4): | $487-90$

39. Conlisk EA, Lengerich EJ, Demark-Wahnefried W, Schildkraut JM and Aldrich TE Prostate cancer: demographic and behaviora correlates of stage at diagnosis among blacks and whites in North Carolina Urology 1999, 53(6): I 194-9

40. Waterbor JW and Bueschen AJ Prostate cancer screening (United States) Cancer Causes Control 1995, 6(3):267-74

4I. Merrill RM, Feuer EJ, Warren JL, Schussler N and Stephenson RA Role of transurethral resection of the prostate in populationbased prostate cancer incidence rates Am J Epidemiol 1999, I 50(8):848-60

42. Lyon JL, Gardner K and Gress RE Cancer incidence among Mormons and non-Mormons in Utah (United States) 1971-85 Cancer Causes Control 1994, 5(2): |49-56

43. Catalona $W J$ and Bigg SW Nerve-sparing radical prostatectomy: evaluation of results after 250 patients J Urol 1990, I 43(3):538544

44. Merrill RM Upstaging of prostate cancer due to radical prostatectomy in the United States: a population-based analysis UroOncology 200I, I:243-50

\section{Pre-publication history}

The pre-publication history for this paper can be accessed here: http://www.biomedcentral.com/1471-2407/3/14/prepub

Publish with Bio Med Central and every scientist can read your work free of charge

"BioMed Central will be the most significant development for disseminating the results of biomedical research in our lifetime. "

Sir Paul Nurse, Cancer Research UK

Your research papers will be:

- available free of charge to the entire biomedical community

- peer reviewed and published immediately upon acceptance

- cited in PubMed and archived on PubMed Central

- yours - you keep the copyright
BioMedcentral 